\title{
Research on power electronics teaching case based on the simulation of frequency converter
}

\author{
Zhilin DING ${ }^{1}$, Shuling FENG ${ }^{1}$, Wenping BU ${ }^{1}$ \\ ${ }^{1}$ College of Electrical and Information Engineering,Nanchang Institute of Science and Technology, \\ Jiangxi Nanchang, 330108, China. \\ agold_my_fency@163.com
}

Keywords: power electronics; inverter; MATLAB/SIMULINK.

Abstract. Based on the course of power electronics technology, the principle and results of the AC-DC-AC circuit of the inverter structure are analyzed via experiment and simulation. Through the comparison of designing and MATLAB/SIMULINK simulation, we can improve comprehensive ability of practice and the ability of EDA designing.

\section{Introduction}

Power electronics technology is a practical course, which is relative to the lack of hardware resources in Colleges and Universities. [1] Computer EDA technology, for example MATLAB/SIMULINK simulation software, can help alleviating this problem. Through the accurate modeling of the case combined with the actual example, which is a comparison of the simulation result and the experimental platform, we can improve the efficiency of the teaching as well as broaden the students' innovation. Through simulation this paper is based on the principle of inverter, which enhance the understanding and application of theory.

\section{Research and development of teaching case on power electronics}

\subsection{Research ideas}

This topic is based on the idea of project teaching research including group comparison and exploration. ${ }^{[2]}$ The main idea of the subject structure as shown in Figure 1, combined with the complementary ways of actual situation and EDA simulation, Figure 2 shown specific implementation steps. Figure 1 can be carried out in different ways, as in a group of different workers or different groups of workers. This can be considered in the study of individual differences in the mode of learning to achieve a certain degree of groups, which enrich the content and vitality of teaching.

In the diagram of Figure 2, through the comparative analysis of the results, the use of experimental platform comparison or feedback to the simulation platform can be compared to the problems in the whole process. [3] For example, through the experiment of the problem placed in the MATLAB/SIMULINK simulation platform, as well as combined with simple experimental cases, we can use MATLAB/SIMULINK simulation results for comparison analysis. ${ }^{[4]}$ At the same time, through the decomposition of the whole project, the curriculum can be run through it, which highlight the integrity of the curriculum in practical, improving the level of modernization.

\section{2 case characteristics}

The characteristic of the case is to introduce the simulation model about grid frequency, which deepen the understanding of the concept between $50 \mathrm{~Hz}$ frequency and $60 \mathrm{~Hz}$ frequency. In order to realize the change of power grid frequency, the converter can be used to improve the utilization ratio of the equipment. 


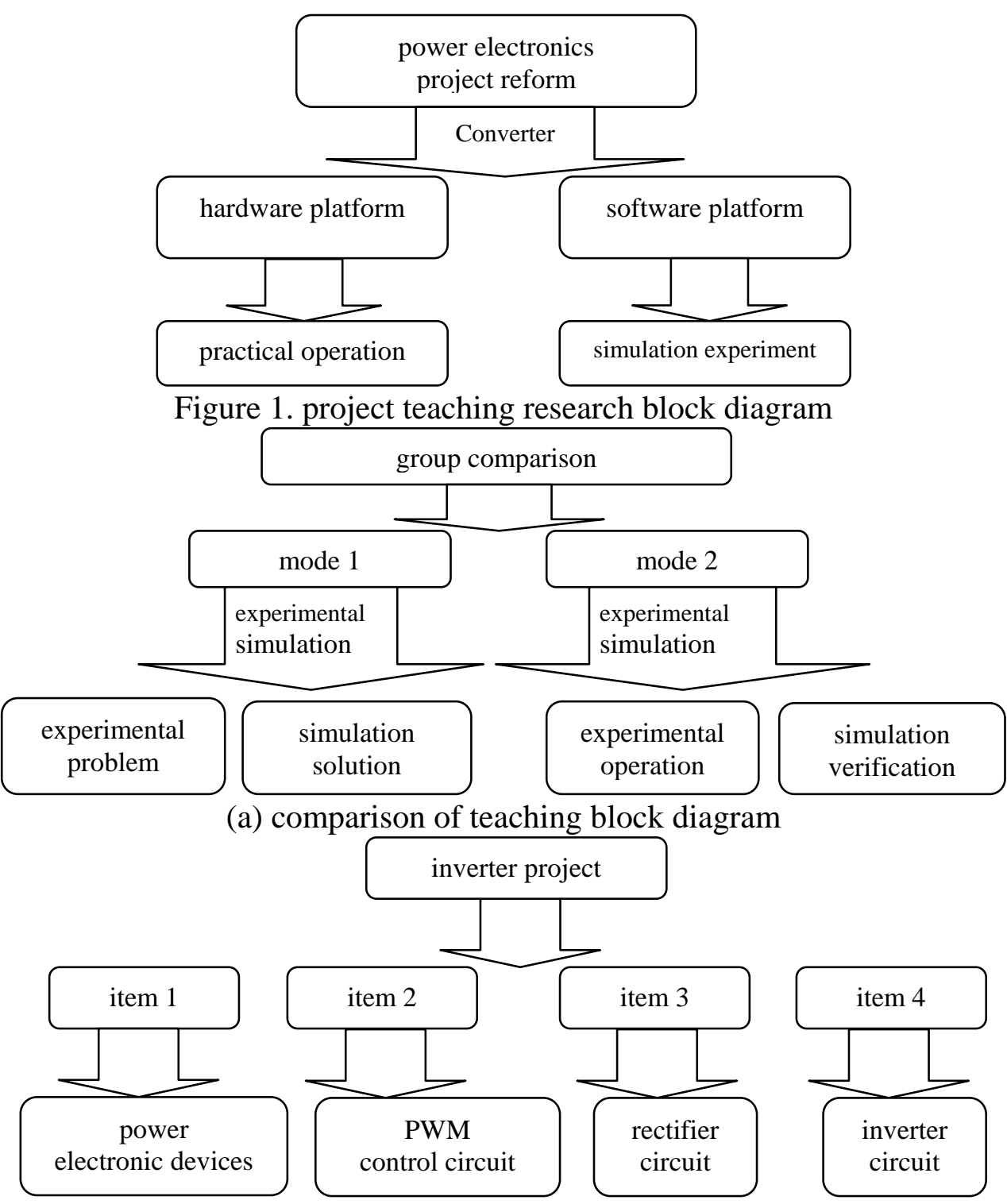

(b) schematic diagram of the inverter project case decomposition

Figure 2. schematic diagram and case decomposition diagram based on group comparison At the same time, the choice of the experimental platform is flexible and diverse, there are a variety of options for group differences. Knowledge points involved in the converter, so dividing the students can choose different levels of free learning module. In this way, we can not only improve the efficiency of learning, but also achieve individualization via the use of students differentiation.

\section{The choice of case development platform for Power Electronics}

Taking MATLAB software as the simulation platform, and combining with the experimental equipment of electric drive Laboratory. In this case, the basic circuit topology of the inverter is used to develop the AC-DC-AC simulation.

\subsection{MATLAB software introduction}

MATLAB software is powerful, which can be used for mathematical algorithms or be used to build a simulation platform. MATLAB/SIMULINK model can call on the power electronics module of the power electronic circuit simulation development.

\subsection{Inverter circuit simulation}

Inverter circuit topology of the basic software simulation diagram shown in Figure 3. Figure 3 (a) is the basic topology simulation, which proposed the power supply frequency of $60 \mathrm{~Hz}$ to the end of the grid frequency $50 \mathrm{~Hz}$ of the entire conversion process, including the AC-DC rectifier conversion and DC-AC inverter conversion. Figure 3 (b) is the basic topology simulation submodule, which is shown as the internal module of the LC filter. Because the inverter side needs to be filtered through the waveform of the inverter, the waveform can be connected to the grid after filtering. 


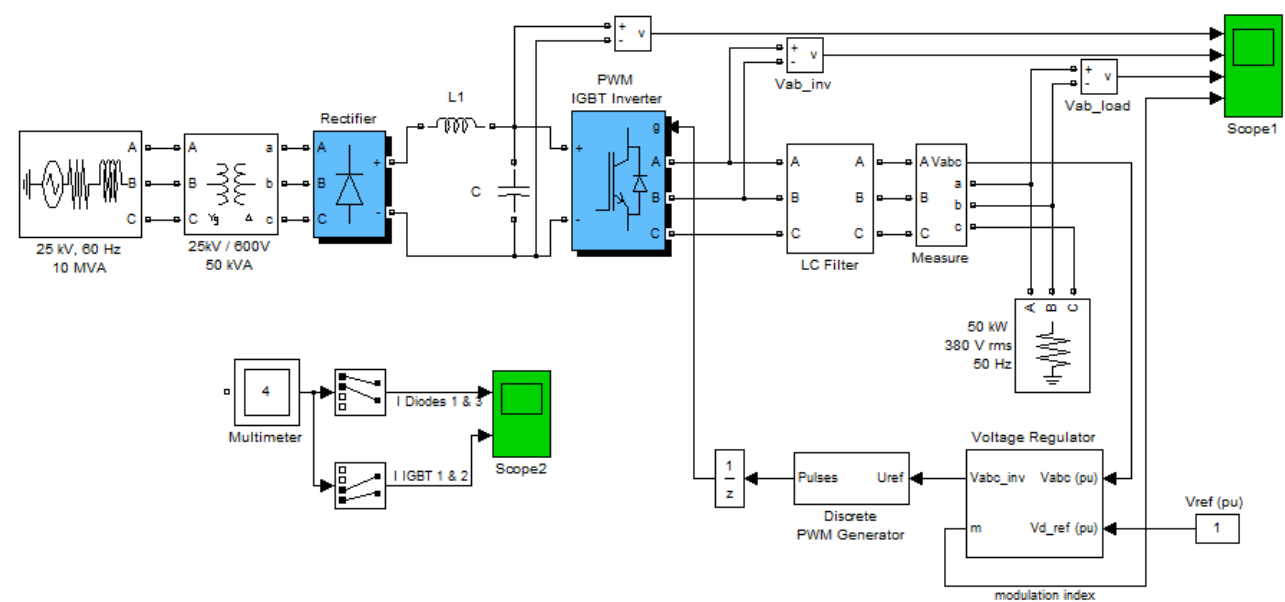

(a) basic topological structure of inverter circuit simulation diagram

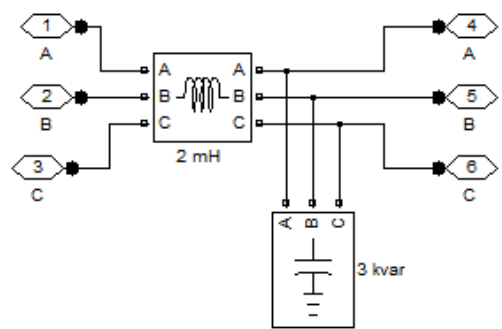

(b) basic topology of the inverter circuit simulation sub module

Figure 3. inverter circuit topology MATLAB software simulation diagram

\subsection{Arrangement of frequency converter circuit}

In the content of the whole converter circuit, the internal structure can be arranged separately. The contents of the arrangement as shown in Figure 4, which is a reference case in this diagram. According to the actual situation of the whole arrangement about the comparative study, the whole part of the inverter will be spun off, which can strengthen the basic concepts, as well as the understanding and mastering of basic knowledge and concept.

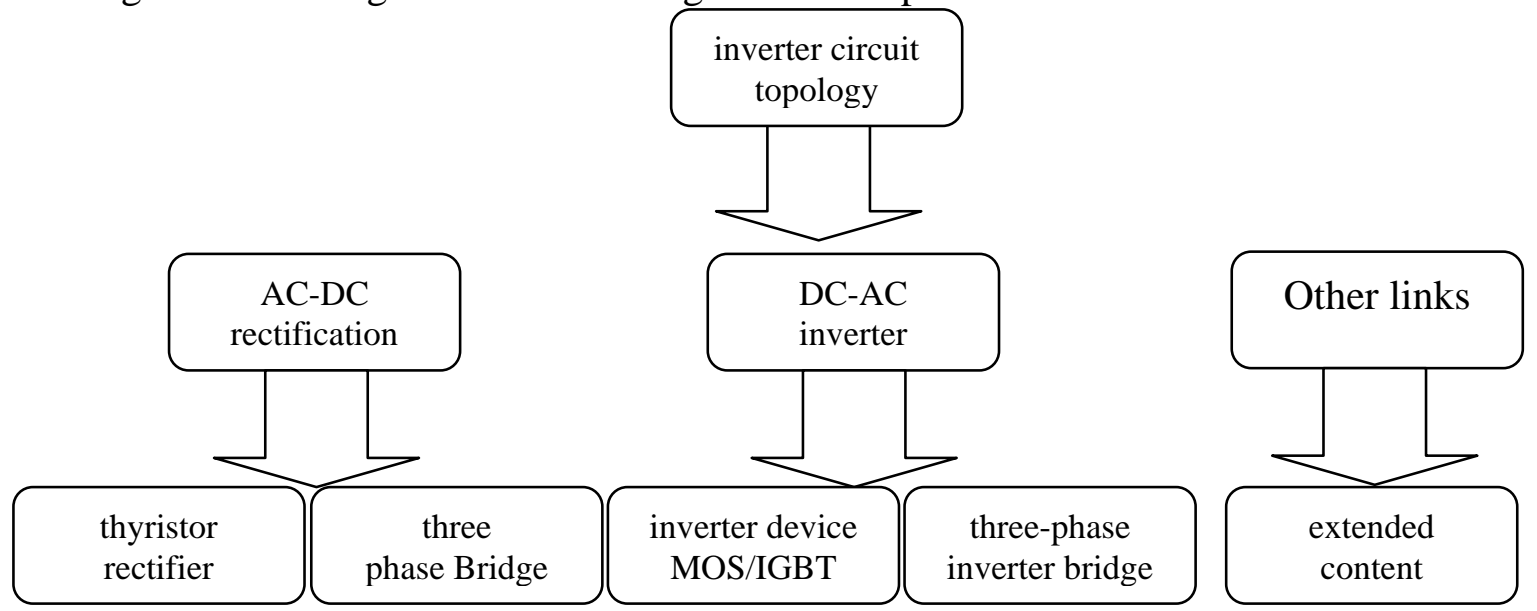

Figure 4. inverter topology teaching content arrangement diagram

\section{Analysis on the effect of power electronics}

The projects proposed a comparative study between the results of MATLAB/SIMULINK simulation and the experiment results from electric drive laboratory of electric power and electronic device platform. MATLAB software simulation waveform results of inverter circuit shown in Figure 5.

Figure 5 (a) is MATLAB simulation output waveform of the inverter circuit, from top to bottom is as follow: the rectifier output voltage waveform, inverter side output voltage waveform, the line side voltage waveform after filtering and modulation voltage waveform. Figure 5 (b) is MATLAB simulation on thyristor current and IGBT current waveform of the inverter circuit. 
For the analysis of the project and the experiment can also be measured with other simulation results, such as the end of primary and secondary side voltage of the transformer. Observing the waveform can also be compared with the experimental waveform, analysis and simulation accuracy, which enhance the capacity and improve the modeling ability.

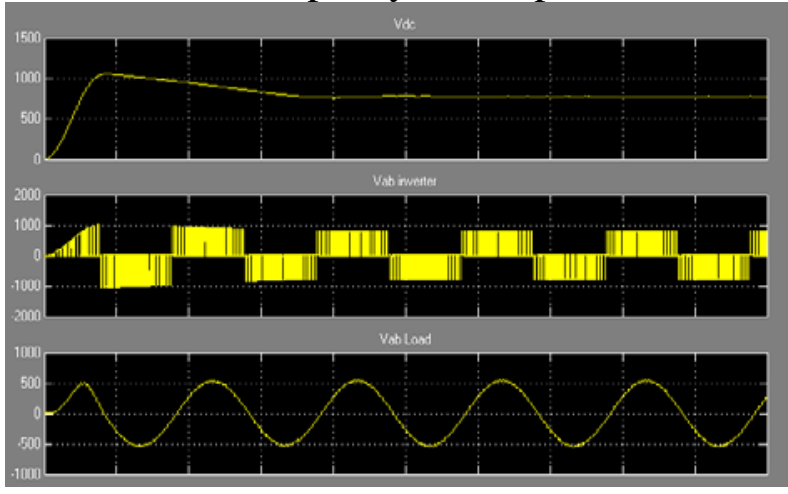

(a) output waveform of inverter

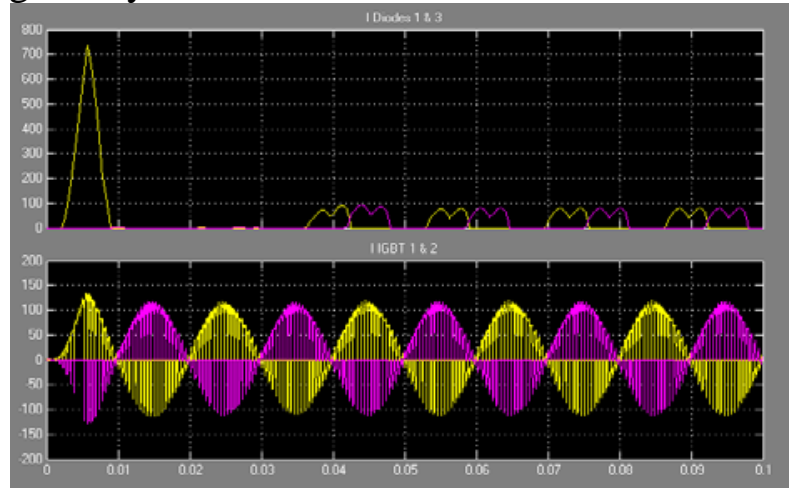

(b) thyristor and IGBT current waveform of inverter

Figure 5. MATLAB software simulation results of inverter circuit

\section{Conclusion}

This paper is based on the power electronics, with the help of a practical application which is typical circuit in the frequency converter equipment. Combined with the MATLAB/SIMULINK software simulation, the project design a case group type module teaching method. The paper draw the following conclusions:

1) By dividing the frequency converter module, the knowledge points can be decomposed, which makes the knowledge points have internal connection and the integrity of knowledge.

2) The working process of the converter module can be obtained by experiment and simulation, and the results of comparative studies enhance practicality.

3) Citing the MATLAB/SIMULINK software simulation, the auxiliary function of the simulation software can improve the efficiency of the item, which enhance the perception and interaction of the curriculum.

Inverter circuit in the case can be combined with the actual situation of the appropriate adjustments. For instance, the amount of hours based on the specific content will be increased or decreased, and somewhat about content depth for outstanding. Simulation results illustrate the rationality of the experiment. According to the simulation waveform, the results can not be easily displayed in the experimental platform, which can not only improve the effectiveness and practicability of the item, but also improve the modernization level of the case.

Acknowledgements: Nanchang Institute of Science and Technology Education reform project(No.NGJG-2015-37).

\section{References}

[1]Case Teaching of Power Electronic Technology Course[J], JOURNAL OF EEE, 2014.6(3).

[2] Application of case teaching method in the teaching of power electronics[J], Computer Education, 2012.2(4).

[3] "Preliminary exploration of case teaching in classroom teaching and research project" the combination of power electronic technology[J], EDUCATION TEACHING FORUM, 2014.4(15). [4] Application of MATLAB/SIMULINK in teaching of power electronics[J], China Electric Power Education, 2014.(9).

[5] Application of SIMULINK in teaching of power electronics [J], China Electric Power Education,2011. (18). 